\title{
Original manuscript by Lebdai et al.: do patients have to choose between ejaculation and miction? A systematic review about ejaculation preservation technics for benign prostatic obstruction surgical treatment
}

\author{
Xiaoye Zhu ${ }^{1}$ (D) Frank C. H. d'Ancona ${ }^{1}$ \\ Received: 26 February 2019 / Accepted: 27 February 2019 / Published online: 5 March 2019 \\ (c) Springer-Verlag GmbH Germany, part of Springer Nature 2019
}

\section{Dear Editor}

With much interest, we read the comprehensive review by Lebdai et al. [1]. Although ejaculation preserving techniques for benign prostatic obstruction surgery such as TURP, photoselective vaporization with the Greenlight laser and holmium laser enucleation have been described for several years now, high-quality controlled studies are scarce. Moreover, questionnaires such as International Index of Erectile Function (IIEF) or Male Sexual Health Questionnaire Ejaculatory Dysfunction (MSHQ-EjD) should be used more often to give us better understanding of the true benefit of these modified techniques. Most importantly, we have to know if the desobstruction is durable as the longest follow-up is 5 years [1].

In addition, we would like to point out that the referred study by Leonardi et al. [2] examined the effect of the sidefiring 980-nm diode laser, and not photoselective vaporization, as the authors noted in their review. As compared to Greenlight, the diode laser comes with an entirely different energy source and wavelength and the resulting laser-tissue interaction. Therefore, these two laser modalities should not be mistaken for each other.

In summary, modifications to existing (enucleation) techniques may offer improvement to ejaculation preservation, although long-term data are lacking regarding maintaining the efficacy of the desobstruction. It appears that whereas minimally invasive techniques such as Urolift, Rezum and Aquablation are promising on the short- and mid-term, their use is limited by factors such as availability, costs and prostate anatomy.

\section{References}

1. Lebdai S, Chevrot A, Doizi S, Pradere B, Delongchamps NB, Benchikh A, Cornu JN, Della Negra E, Fourmarier M, Misraï V, Theveniaud PE, Descazeaud A, Robert G, CTMH-AFU group (2019) Do patients have to choose between ejaculation and miction? A systematic review about ejaculation preservation technics for benign prostatic obstruction surgical treatment. World J Urol 37(2):299-308. https://doi.org/10.1007/s00345-018-2368-6

2. Leonardi R (2009) Preliminary results on selective light vaporization with the side-firing $980 \mathrm{~nm}$ diode laser in benign prostatic hyperplasia: an ejaculation sparing technique. Prostate Cancer Prostat Dis. 12(3):277-280. https://doi.org/10.1038/pcan.2009.5 (Epub 2009 Mar 24)

Publisher's Note Springer Nature remains neutral with regard to jurisdictional claims in published maps and institutional affiliations.
Xiaoye Zhu

xiaoye.zhu@radboudumc.nl

1 Department of Urology, Radboud University Medical Center, Nijmegen, The Netherlands 